\title{
LAS INSTITUCIONES Y SUS PRESUPUESTOS DE INFORMACIÓN EN EL ORDEN SOCIAL. UN ENFOQUE ECONÓMICO
}

\section{THE INSTITUTIONS AND ITS BUDGETS OF INFORMATION IN THE SOCIAL ORDER. AN ECONOMIC FOCUS.}

\author{
Por: Diego Rengifo Lozano ${ }^{1}$
}

Fecha de recepción: 15 de junio de 2010

Fecha de aprobación: 30 de julio de 2010

\section{Resumen}

Este artículo pretende, mediante la aproximación de los discursos económico y jurídico, presentar los presupuestos de información necesarios para la formulación de un orden social definiendo a qué clase de individuo se alude como sujeto "informado" y qué clase de información requiere para sustentar sus esquemas de racionalidad frente a la estructura institucional.

\footnotetext{
${ }^{1}$ Economista y Especialista en Derecho Privado Económico de la Universidad Nacional, Magíster en Derecho de la Universidad de los Andes, Doctorado (c) en Sociología Jurídica e Instituciones Políticas de la Universidad Externado de Colombia. Profesor de la Facultad de Derecho de la Universidad Santo Tomás. E-mail: drengifol@hotmail.com
} 


\section{REVISTA VIRTUAL VIA INVENIENDI ET IUDICANDI \\ "CAMINO DEL HALLAZGO Y DEL JUICIO"}

http://viei.usta.edu.co/ E-MAIL: revistainveniendi@usantotomas.edu.co

Palabras claves. Instituciones, institucionalismo, descentralización, contratos, Teoría de juegos, economía de la información, competencia, asimetría, incertidumbre, azar

\section{Abstract}

This article examines, by means of converging economic and legal discourses, the assumptions of necessary information for the social order formulation, which includes clarity about what kind of individuals most be refering as "informed", and also what kind of information seems to be required in order to founded his rationality patterns regarding the institutional structure.

Key words. Institutions, decentralization, contracts, Theory of games, economy of the information, competition, asymmetry, uncertainty, chance

El acervo de "instrumentos" ideados por el hombre y que constituye parte importante de su adaptación al mundo que le rodea comprende mucho más que herramientas materiales. En gran medida está integrado por formas de conducta que habitualmente seguimos sin saber por qué, las denominadas tradiciones e instituciones que utilizamos porque están a nuestro alcance como producto de un crecimiento acumulativo y sin que jamás hayan sido ideadas por una sola inteligencia. 


\section{REVISTA VIRTUAL VIA INVENIENDI ET IUDICANDI \\ "CAMINO DEL HALLAZGO Y DEL JUICIO"}

http://viei.usta.edu.co/ E-MAIL: revistainveniendi@usantotomas.edu.co

Generalmente, el hombre no sólo ignora por qué usa los instrumentos a su disposición de una forma o de otra, sino también hasta qué grado depende de que sus acciones tomen una determinada forma en vez de otra distinta. Usualmente desconoce hasta qué punto el éxito de sus esfuerzos viene determinado por su conformidad con hábitos de los que ni siquiera es sabedor.

Friedrich Hayek

Los fundamentos de la libertad

\section{Introducción}

Joseph Schumpeter parece no llegar a una definición concreta acerca de si es Adam Smith el Beccaria escocés o Cesare Beccaría el Adam Smith italiano (1984, p. 176-177). De todas maneras, la economía puede apreciar en De los delitos y de las penas un sistema racional de pagos anterior al de La Riqueza de las Naciones, así como el derecho puede ver en el sistema de precios un estatuto social independiente de cualquier pretensión racionalista o voluntarista. Al igual que la usual dicotomía entre equidad y eficiencia, este predicamento sirve de referencia sobre la indeterminación de los límites expuestos por las áreas jurídica y económica en un intento de apropiación de sus respectivos objetos de 


\section{REVISTA VIRTUAL VIA INVENIENDI ET IUDICANDI \\ "CAMINO DEL HALLAZGO Y DEL JUICIO"}

http://viei.usta.edu.co/ E-MAIL: revistainveniendi@usantotomas.edu.co

conocimiento. Son más bien abundantes los textos que señalan la inconveniencia de este divorcio, sea debido a la ausencia de categorías de análisis que puedan interesar terrenos comunes, a la diversidad de lenguaje, o tristemente al instinto primitivo de establecer los elementos del saber-poder en términos de alguna hipotética territorialidad. George Stigler, el bautista del Teorema de Coase, Ilama la atención sobre los matices que puede tomar la vinculación de estas áreas:

Las políticas económicas no son fácilmente distinguibles de otras políticas por ejemplo, las educativas o las de defensa nacional- por lo que, a menudo, el abogado y el economista deben hacerle espacio a personas tan ambiguas como el sociólogo y el oficial militar. En estas ocasiones el abogado y el economista se vuelven más amistosos y cooperativos: no hay nada como un adversario mutuo para unir a la gente. Ésta es la razón por la que las familias con hijos son más duraderas (2000, p. 592).

Aun dejando de lado estas incómodas consideraciones, emerge la sana inquietud acerca de qué elementos económicos pueden, y hasta qué punto, estimar el orden de las instituciones en relación con los circuitos de información de la sociedad. La respuesta a este interrogante gira en torno a una inquietud fundamental respecto a los datos comunicados por esa interacción social, así en el campo jurídico como en el económico: la información de los individuos como presupuesto de su racionalidad. 


\section{REVISTA VIRTUAL VIA INVENIENDI ET IUDICANDI \\ "CAMINO DEL HALLAZGO Y DEL JUICIO"}

http://viei.usta.edu.co/ E-MAIL: revistainveniendi@usantotomas.edu.co

El estudio de los comportamientos individuales realizado por la economía tradicional demuestra, bajo su propio lenguaje, que la "soberanización" de los agentes económicos (homo economicus) es un presupuesto fundamental de la sociedad moderna, evaluada en unos términos de eficiencia tales que desbordan la propia esfera económica y se ofrecen a otros campos como la sociología, la política y el derecho. El soporte teórico del modelo se halla, a su vez, en un área particular de la economía, la microeconomía, cuyo objeto es el estudio los entes de decisión individual. Este tipo de lectura, acorde con el individualismo metodológico y un esquema social atomístico, se sustenta en dos pilares fundamentales: la instrumentación de la lógica matemática en la lectura de la realidad social, y la admonición de un orden trascendente que supera así la voluntad como la razón de sus participantes. Este individualismo metodológico se aviene a las diversas falanges del liberalismo en virtud del nivel de integralidad de un modelo social manifestado a través de un orden eficiente, derivado de la soberanización de los agentes. La Mont Pelerin Society que a mediados del Siglo XX agrupó a pensadores como Ludwig Von Mises, Karl Popper, Milton Friedman, Aaron Director, Frank H. Knight, George Stigler y Friedrich Hayek, entre otros, mostró la reacción del liberalismo en momentos en que la suerte del "mundo libre" se hallaba, por decirlo de alguna manera, sujeta a entredichos diferentes a los que asistimos hoy día. El círculo ideológico reunido en aquel entonces giraba alrededor de la más abierta denuncia al "constructivismo" estatal que monopolizaba la información y la racionalidad social mediante los "dictados" del poder central y que 


\section{REVISTA VIRTUAL VIA INVENIENDI ET IUDICANDI}

"CAMINO DEL HALLAZGO Y DEL JUICIO"

http://viei.usta.edu.co/ E-MAIL: revistainveniendi@usantotomas.edu.co

parecía expandirse por el mundo a un ritmo alarmante. Ya Popper y Hayek habían advertido el peligro en sus textos La miseria del Historicismo y Camino de servidumbre respectivamente, ambos publicados en 1944. El primero trata sobre la imposibilidad de la predicción histórica racionalista negando la cientificidad del determinismo no solo hegeliano-marxista sino también de la pretendida legitimación histórica del Tercer Reich. El segundo muestra cómo la planificación y la centralización de la información, en los niveles registrados en la época, conducen a modelos totalitarios como parte de su propia mecánica, una suerte de Vía Crucis para las sociedades de mercado, ya de por sí agobiadas por un elemento disociador y, en términos de ingeniería social, igualmente incómodo: la intervención estatal.

Muchas décadas después, a finales de los ochenta cuando Keynes, de quien Hayek fue eterno contradictor, era recordado como un remoto ilusionista cuyos milagros fomentaban la inflación, y cuando la amenaza del socialismo había cedido su alcázar a la recomposición del orden mundial, Hayek escribe La fatal arrogancia, donde a manera de corolario podemos ubicar el verdadero y constante peligro denunciado en su larga producción, más allá del desplome del experimento soviético: el racionalismo constructivista. A continuación, intentaremos una aproximación a este núcleo de problemas desde las condiciones que presenta el debate en la encrucijada entre la economía y el derecho. 


\section{REVISTA VIRTUAL VIA INVENIENDI ET IUDICANDI \\ "CAMINO DEL HALLAZGO Y DEL JUICIO"}

http://viei.usta.edu.co/ E-MAIL: revistainveniendi@usantotomas.edu.co

\section{Descentralización}

El principal elemento que aborda Hayek para denunciar la imposibilidad de un estatuto racionalista está dado por un complejo informacional de datos descentralizados, atomizados y dispersos, "un conocimiento que no está dado a nadie en su totalidad" (Hayek, 1999, p. 334). Posición acorde con el Teorema Austríaco de la Imposibilidad, según el cual no le es posible a un agente, sea público o privado, disponer de toda la información requerida para una asignación eficiente de los recursos. La dispersión informacional en cada uno de los individuos es variable y se recompone en diferentes escenarios de tiempo y lugar, lo que convierte cualquier aproximación en un elemento conjetural. El derecho y la economía coexisten bajo el influjo de la misma pretensión de la razón, como que se trata de otra modalidad imperial, y que además lleva implícito el riesgo de su propio desequilibrio: “¿La razón? ¡Yo me considero racional, pero parto de la idea de que la razón es evolutiva y que lleva en sí misma a su peor enemigo! Es la racionalización la que corre el peligro de sofocarla" (Morin, 1996, p. 162). Aunado a este predicamento, el problema se recrudece cuando se establecen diferentes racionalidades y esquemas valorativos de interpretación, tal y como sucede con el derecho y la economía ${ }^{2}$. Justamente el aporte de Hayek a este respecto se halla en la consonancia de los lenguajes informacionales bajo la teoría del orden

\footnotetext{
2 "La razón se disocia en una pluralidad de esferas de valor destruyendo su propia universalidad". Max Weber, citado por Jürgen Habermas en Teoría de la Acción Comunicativa, Buenos Aires, Taurus, 1990, t. I, p. 321.
} 


\section{REVISTA VIRTUAL VIA INVENIENDI ET IUDICANDI \\ "CAMINO DEL HALLAZGO Y DEL JUICIO"}

http://viei.usta.edu.co/ E-MAIL: revistainveniendi@usantotomas.edu.co

espontáneo, en el sentido de un orden natural mediado no por recursos racionalistas sino precisamente por su derivación hacia la descentralización de la información como insumo del conocimiento social: "El rasgo peculiar del problema de un orden económico racional consiste, justamente, en que el conocimiento de las circunstancias que debemos utilizar nunca existe en forma concentrada 0 integrada sino como fragmentos dispersos de conocimiento incompleto y frecuentemente contradictorio, que los individuos poseen por separado" (Hayek, 1999, p. 333). A este tenor, el campo de la institucionalidad jurídica debe proveer un "mínimo" de términos de conducta, producto de procesos naturales antes que convencionales, los cuales conformarán un orden de mayor consistencia que aquellos inspirados en la deliberación y el diseño institucional.

Nada distingue con más claridad las condiciones de un país, libre de las que rigen en un país bajo un gobierno arbitrario, que la observancia, en aquél, de los grandes principios conocidos bajo la expresión Estado de Derecho. Despojada de todo su tecnicismo, significa que el Estado está sometido en todas sus acciones a normas fijas y conocidas de antemano; normas que permiten a cada uno prever con suficiente certidumbre cómo usará la autoridad en cada circunstancia sus poderes coercitivos, y disponer los propios asuntos individuales sobre la base de este conocimiento (Hayek, 1986, p. 103). 


\section{REVISTA VIRTUAL VIA INVENIENDI ET IUDICANDI \\ "CAMINO DEL HALLAZGO Y DEL JUICIO"}

http://viei.usta.edu.co/ E-MAIL: revistainveniendi@usantotomas.edu.co

Catalaxia fue el término acuñado por Hayek para denotar el orden espontáneo en la sociedad, concepto que debe ser rescatado de la confusión más común respecto de sus alcances: su asimilación al orden económico. La economía prevé una jerarquización de objetivos y fines alrededor de los cuales se aglutinan las fuerzas sociales pertinentes, determinando con ello la distribución de los recursos. Pero existe un riesgo en el hecho de ordenar las preferencias sociales de la misma forma que se evidencia en la estructura económica: la pretensión y disposición mecánica sobre la información, cual es el caso tanto del proyecto socialista como de la economía neoclásica ortodoxa, pues ambos discursos manejan la catalaxia como si se tratara de una economía con arreglo a fines unitarios.

El problema central de la catalaxia, y de la teoría económica entendida correctamente, es la división del conocimiento en la sociedad, es decir, cómo lograr que el conocimiento, disperso y repartido entre millones de agentes económicos, pueda volverse accesible a muchos. Este es el verdadero papel del proceso de mercado: no el de economizar los medios escasos destinados a fines conocidos, sino más bien el de generar por medio del mecanismo de precios, información sobre la manera en que los agentes económicos, desconocidos entre sí, pueden alcanzar de la mejor forma sus propósitos, igualmente desconocidos (Gray, 1994, p. 108). 


\section{REVISTA VIRTUAL VIA INVENIENDI ET IUDICANDI \\ "CAMINO DEL HALLAZGO Y DEL JUICIO"}

http://viei.usta.edu.co/ E-MAIL: revistainveniendi@usantotomas.edu.co

Por tanto, los términos de referencia jurídicos representan, además, la necesidad de establecer más que normas de conducta mediadas por un ideal ético de justicia, un lenguaje articulado con el cual la información y el conocimiento puedan circular entre los individuos de forma que puedan llevar a cabo la coordinación de la acción social. La norma es, pues, un recurso de coordinación al que se obligan los individuos en aras de establecer un nivel de seguridad mínimo asociado a la información. Ahora bien, la cuestión está en precisar los niveles de eficiencia alcanzados por sistemas de información centralizados o descentralizados en las asociaciones humanas. A esta disyuntiva acuden en cierto nivel de tensión la planificación y la libre iniciativa, los monopolios y la "competencia", e incluso el derecho común y el estatutario.

El más eficiente de estos sistemas será el que permita esperar un uso más pleno del conocimiento existente. Esto depende, a su vez, de si hay mayor probabilidad de éxito cuando todo el conocimiento que se debe utilizar, pero que inicialmente está disperso entre muchos individuos diferentes, se pone a disposición de una autoridad central o cuando se transmite a los individuos el conocimiento adicional que requieren para que puedan acoplar sus planes con los de los demás (Hayek, 1986, p. 335).

Este mecanismo inconsciente de coordinación proviene de la tesis smithiana según la cual la intervención de voluntades concebidas al margen del mercado da 


\section{REVISTA VIRTUAL VIA INVENIENDI ET IUDICANDI \\ "CAMINO DEL HALLAZGO Y DEL JUICIO"}

http://viei.usta.edu.co/ E-MAIL: revistainveniendi@usantotomas.edu.co

origen a desequilibrios ulteriores en virtud de que toda aproximación exógena, proveniente de circuitos centralizados (entiéndase el Estado, las asociaciones y cualquier otro bloque informacional) entorpece las libres fuerzas originadas y desplegadas bajo el lenguaje de la oferta y la demanda. De este modo, los sistemas políticos inspirados en teorías liberales han establecido cierta hegemonía del derecho privado sobre el derecho público, buscando reducir el marco de acción estatal y estimulando la libre iniciativa y la eficiencia que suponen sus actividades guiadas por el beneficio individual como estándar de conducta.

Al interior del proceso social, la actividad económica debe ser ejercida con plena sujeción a la ley, así su dinámica natural se rija por leyes de origen diferente que pueden chocar con el esquema normativo, como se puede apreciar en el largo proceso histórico de adecuación legal a los requerimientos de la usura (a favor de la cual se pronunciara Jeremy Bentham). Estas leyes no expresan más que una realidad: la pretensión de los agentes económicos y su evaluación mediada por el beneficio, o entre el placer y el dolor, de suerte que no existe mejor juez de sus respectivos intereses que el individuo mismo. Si bien las acciones humanas generan sucesos que escapan a su vaticinio y aun a su entendimiento, la mano invisible se halla presta a conjurar cualquier desequilibrio siempre y cuando se le permita operar en su debida dimensión. La descentralización es una de sus exigencias y, por ende, la incertidumbre uno de sus instrumentos. No existe un ente capaz de manejar la información necesaria y suficiente. De tal suerte, entre 


\section{REVISTA VIRTUAL VIA INVENIENDI ET IUDICANDI \\ "CAMINO DEL HALLAZGO Y DEL JUICIO"}

http://viei.usta.edu.co/ E-MAIL: revistainveniendi@usantotomas.edu.co

Smith y Hayek existe un vínculo en el orden natural expresado en términos ajenos a la voluntad y la razón, dos lenguajes bajo los cuales el hombre se ha leído en sociedad y a partir de su racionalidad ha diseñado y construido sus instituciones.

Es con el surgimiento del derecho consuetudinario (common law) en Inglaterra que las insinuaciones escolásticas de un derecho natural antirracionalista se transforman en un cuerpo de jurisprudencia sustantiva. Aquí la figura central es Sir Matthew Hale (1609-1676), quien argumentaba que el common law poseía un mayor grado de sabiduría y racionalidad que las teorías jurídicas aprioristas y antitradicionalistas, precisamente porque tomaba en cuenta hechos y circunstancias inasequibles para la razón pura. Con el desarrollo de este argumento, inauguró una tradición de jurisprudencia que usualmente asociamos con Adam Smith y Edmund Burke, y hoy en día con Hayek. La tesis principal de estos autores es que, en algún sentido $u$ otro, el derecho genuino no es creado sino descubierto ${ }^{3}$.

\section{Información y competencia}

El tratamiento dado por Hayek a la información, que suscitó el enfrentamiento de la economía tradicional, sobre todo de la escuela austríaca, contra el proyecto

\footnotetext{
3 Barry, Norman (1997). "La tradición del orden espontáneo". Revista Acta Académica, Universidad Autónoma de Centroamérica. Recuperado el 12 de agosto de 2000, de http://www.uaca.ac.cr/acta/1997nov/norman.htm
} 


\section{REVISTA VIRTUAL VIA INVENIENDI ET IUDICANDI \\ "CAMINO DEL HALLAZGO Y DEL JUICIO"}

http://viei.usta.edu.co/ E-MAIL: revistainveniendi@usantotomas.edu.co

marxista, desbordó sus escenarios hasta tal punto que los argumentos sobre la imposibilidad del control planificador, ora del mundo socialista ora del Estado interventor, pueden aplicarse en igual forma a las organizaciones empresariales. A partir de entonces, el embate contra el supuesto fundamental de la economía, cual es el modelo de competencia perfecta, no se hizo esperar; y el terreno para el análisis de la economía de la incertidumbre, y posteriormente de la información, estaba abonado. Tres premisas fundamentales formulan el problema de la información: la cantidad y diversidad de la información es inconmensurable como para ser manejada por un ente particular (una suerte de planificador principal), el carácter dinámico de los sucesos impide la utilización de información que aún no se ha producido ${ }^{4}$ y con ellos la evidencia de la asimetría e incompletitud de la información como origen de su carácter mercantil. Despojando a la "competencia" de la acepción corriente, que implica su aproximación pesimista a tendencias predatorias, nos limitaremos a su lectura a partir de la descentralización y dispersión de la influencia que los agentes pueden imprimir a la dinámica de los mercados.

Suele considerarse al darwinismo como una filosofía cruel: describe la "naturaleza a sangre y fuego"; es decir, una imagen en la que la naturaleza plantea una amenaza hostil hacia nosotros y hacia la vida en general. En mi

\footnotetext{
${ }^{4}$ En este contexto, Galbraith sostiene que el sistema económico sobrevive no a causa de la excelencia de la labor de quienes pronostican su futuro, sino gracias a su inquebrantable tendencia al error. Cf. Historia de la economía, Barcelona, Ariel, 1992, p. 14.
} 


\section{REVISTA VIRTUAL VIA INVENIENDI ET IUDICANDI}

"CAMINO DEL HALLAZGO Y DEL JUICIO"

http://viei.usta.edu.co/ E-MAIL: revistainveniendi@usantotomas.edu.co

opinión ésta es una imagen prejuiciosa del darwinismo, que ha estado influida por una ideología que existía antes de Darwin (Malthus, Tennyson, Spencer) y que no tiene casi nada que ver con el contenido teórico real del darwinismo. Cierto es que el darwinismo pone un gran énfasis en lo que denominamos "selección natural"; pero también esto puede interpretarse de forma bastante diferente. Según sabemos, Darwin estuvo influido por Malthus, quien intentó demostrar que el aumento de la población, unido a la escasez de alimentos, daría lugar a una competencia cruel, a la selección de los más fuertes y a la cruel aniquilación de los no tan fuertes. Pero según Malthus, incluso los más fuertes están sometidos a presión por la competencia: se ven forzados a aplicar todas sus energías. De aquí que, según esta interpretación, la competencia determina la limitación de la libertad (Popper, 1994, p. 28).

Carl Menger, abogado austríaco, junto a Stanley Jevons y León Walras conforman los pilares de la escuela económica marginalista. El marginalismo postula que el valor de las mercancías no procede de la teoría del valor-trabajo que había sido defendida por los clásicos sino que resulta de la subjetividad de los individuos. En el modelo walrasiano del mercado, los precios son anunciados por un subastador mientras los agentes, productores y consumidores son esencialmente receptores de esos precios que consideran dados, e inmodificables por medio de una voluntad particular; y se limitan a comunicarle sus pretensiones al subastador en 


\section{REVISTA VIRTUAL VIA INVENIENDI ET IUDICANDI \\ "CAMINO DEL HALLAZGO Y DEL JUICIO"}

http://viei.usta.edu.co/ E-MAIL: revistainveniendi@usantotomas.edu.co

una dinámica de tanteo, como una subasta en la cual los participantes comunicaran sus ofertas exclusivamente al subastador sin que los demás alcancen a percibir la información registrada. Cuando el subastador encuentra el nivel de precios que iguala la cantidad de productos ofrecidos con los demandados es cuando se realizan los intercambios. En este aislamiento estratégico que supone el modelo, las decisiones desconocidas por los demás agentes no afectan el bienestar del colectivo ya que cada uno de ellos es sólo un dato muy pequeño, incapaz de alterar por sí solo el desempeño del mercado. El mismo modelo es asumido por Rawls para solucionar los escollos surgidos de las diversas concepciones de justicia, en términos de unanimidad:

...podemos contemplar el acuerdo en la posición original desde el punto de vista de una persona seleccionada al azar. Si cualquiera, después de reflexionar debidamente, prefiere una concepción de justicia a otra, entonces todos lo harán pudiéndose obtener un acuerdo unánime. Podemos imaginarnos, con objeto de hacer más reales las circunstancias, que se exige que las partes se comuniquen unas con otras por medio de un árbitro como intermediario, y que éste ha de anunciar qué alternativas se han sugerido y las razones ofrecidas en su favor. Este árbitro prohíbe cualquier intento de formar coaliciones e informa a las partes cuando han llegado a un entendimiento (Rawls, 1997, p. 137). 


\section{REVISTA VIRTUAL VIA INVENIENDI ET IUDICANDI \\ "CAMINO DEL HALLAZGO Y DEL JUICIO"}

http://viei.usta.edu.co/ E-MAIL: revistainveniendi@usantotomas.edu.co

La economía de la información conforma una nueva visión que se aparta de la economía tradicional basada en los supuestos del modelo de competencia perfecta. Para la nueva microeconomía, por el contrario, la información no es un dato dispensado por el sistema de precios en forma suficiente, ni se puede asumir la completitud de su cubrimiento, por lo cual su crítica se dirige a la estructura fundamental de la lectura económica ortodoxa: la competencia perfecta, cuyo modelo se compone de cuatro supuestos básicos generalmente reconocidos.

1. Los precios son un dato inmodificable a nivel individual. Esto implica la inexistencia de posiciones dominantes en el mercado, y por ende de inferioridad, resultado de la presencia de infinitos consumidores y productores en el mercado. En estos términos un mercado imperfecto o no competitivo expresa la insuficiencia de agentes dispuestos a ofrecer los bienes que se reclaman o bien de agentes dispuestos de demandar los bienes ofrecidos. Ambas circunstancias pueden presentar casos como los que resultan de la concurrencia al mercado de un solo productor (monopolio) o de un solo comprador (monopsonio), lo cual implica una relación de poder expresada en la facultad de manejar los precios a su acomodo, un contrato en el que el conglomerado al que se enfrenta este agente se halla en una posición de inferioridad evidente. El modelo, entonces, resuelve un problema de poder según el cual los agentes no concurrirían al intercambio en igualdad de condiciones, sino que por el contrario establece, soportado en el supuesto de la infinidad de agentes económicos, la igualdad frente a los precios. Esta igualdad se 


\section{REVISTA VIRTUAL VIA INVENIENDI ET IUDICANDI \\ "CAMINO DEL HALLAZGO Y DEL JUICIO"}

http://viei.usta.edu.co/ E-MAIL: revistainveniendi@usantotomas.edu.co

traduce no en propósitos de equidad sino en términos de una competencia integral en la que cada agente es, estadísticamente, despreciable respecto a su participación en el mercado. Así pues, los precios son un dato, una información que no puede ser alterada de manera individual y que en últimas representa un parámetro acordado por las libres fuerzas de la oferta y la demanda.

2. Homogeneidad del producto. Consiste en la igualación absoluta de todos los géneros de mercancías. La gasolina, por ejemplo, es un bien no diferenciable en el caso de ser comparada en las diferentes unidades económicas que la dispensan. Las empresas, al ofrecer un producto idéntico se hallan imposibilitadas para manejar precios diferenciados, garantizando con ello un precio único en el mercado, de tal forma que una unidad productiva que pretenda elevar los precios precipita su demanda a la disminución.

3. Movilidad perfecta de los recursos. Implica la inexistencia de barreras que impidan cambiar la esfera económica en que el agente se desempeña. La razón por la que un agente estaría dispuesto a esta nueva asignación de sus recursos (reasignación) no es otra que el descubrimiento de una nueva en cuyos escenarios puede lograr ganancias más elevadas. Se trata de una facultad de movimiento constante y sin reservas que le facilita así al agente la entrada en otra esfera económica en aras de obtener un mayor nivel de rendimiento, como la salida de ella en caso de resultar fallida su elección. "La condición de perfecta 


\section{REVISTA VIRTUAL VIA INVENIENDI ET IUDICANDI \\ "CAMINO DEL HALLAZGO Y DEL JUICIO"}

http://viei.usta.edu.co/ E-MAIL: revistainveniendi@usantotomas.edu.co

movilidad equivale a una situación en la cual todos los productores de todos los productos son potencialmente productores de cualquier producto" (Cuevas, 1993, p. 34).

4. Información perfecta. El cuarto supuesto, esencial para el desarrollo de nuestro análisis, implica que los agentes son conocedores de sus preferencias, del sistema y de los precios a los que se enfrentan, del nivel de ingreso, costos, cantidades de mercancías en intercambio, tecnología y de todas aquellas variables necesarias para ejecutar una elección que pueda tenerse por válida en términos de racionalidad. Atendiendo a la complejidad del universo mercantil, la información es el tejido que mantiene unido el mercado. La perfecta información de los agentes sortea el escollo del desconocimiento de los precios y costos de producir o consumir un artículo determinado, escollo que de no ser resuelto situaría a los agentes en una posición de incapacidad para elegir racionalmente. De igual manera, este tratamiento de la información sostiene los supuestos anteriores dado que un agente económico sin carencias informativas está en situación de adecuarse efectivamente a ellos, es decir que la información, además de establecerse como elemento del modelo, tiene amplia responsabilidad en el soporte de aquellos que lo complementan.

Pero estos supuestos no operan en la realidad y puede asegurarse que ellos no constituyen la regla sino la excepción. Respecto a los precios como un dato 


\section{REVISTA VIRTUAL VIA INVENIENDI ET IUDICANDI \\ "CAMINO DEL HALLAZGO Y DEL JUICIO"}

http://viei.usta.edu.co/ E-MAIL: revistainveniendi@usantotomas.edu.co

existen agentes que pueden variar los precios precisamente porque no están en presencia de infinidad de agentes rivales sino de unos pocos o de ninguno, como sucede con el monopolio cuya responsabilidad en los desajustes del mercado ha promovido toda una serie de leyes anti trust; la diferenciación de los productos genera nuevas tecnologías y diseños en aras de la captación de un número mayor de consumidores, amparando la no-información o el secreto de sus avances tecnológicos mediante una estructura de derechos de propiedad (industrial, intelectual, etc); la perfecta movilidad de factores es un fenómeno que no puede observarse más que en contados casos como la bolsa de valores y en virtud de la velocidad de sus circuitos; y la información perfecta no deja de presentar una imposibilidad práctica que ha dado origen a la principal ruptura con la microeconomía tradicional. Tal y como se explicó anteriormente, si el supuesto fundamental en que descansa el modelo de competencia es la información, de igual manera los embates habrán de enfilarse en su misma dirección.

\section{Institucionalismo económico}

El modelo de competencia perfecta se consideró útil para un desarrollo teórico y analítico pero se mostró insuficiente para responder y adecuarse a los mecanismos reales de la vida económica. En respuesta a estos requerimientos, surgen primero la economía institucional con representantes como Thorstein Veblen y John Commons, quienes comienzan a apreciar la importancia de las 


\section{REVISTA VIRTUAL VIA INVENIENDI ET IUDICANDI \\ "CAMINO DEL HALLAZGO Y DEL JUICIO"}

http://viei.usta.edu.co/ E-MAIL: revistainveniendi@usantotomas.edu.co

instituciones como elementos fundamentales de la actividad económica, proponiendo con ello una visión más amplia y compleja de los fenómenos sociales, aportes decisivos en la apertura del análisis a nuevas categorías expresadas en valores, hasta cierto punto, considerados ajenos al metadiscurso económico: las instituciones. Una muestra de esas vertientes puede hallarse en Herbert Simon, quien mediante el concepto de "racionalidad limitada" afirma que "las elecciones racionales y maximizadoras de los individuos son restringidas o limitadas por las instituciones y los valores existentes, así como por sus limitadas capacidades de conocimiento, información y cálculo" 5 .

Pese a la generalidad del término, vaguedad que ha provocado graves imprecisiones y controversias, el concepto de "instituciones" no sólo se convirtió en eslabón entre los discursos económico y jurídico (separados por mucho tiempo en virtud del estigma del primero debido a su carácter sesgadamente subjetivo, al igual que el segundo por su pretensión racionalista del deber ser) sino que demostró la necesidad inapelable de su concurrencia. Para Thorstein Veblen "La evolución de la estructura social ha sido un proceso de selección natural de instituciones" (1992, p. 194), entendidas como observaciones generales y, hasta cierto punto, predecibles del comportamiento social. Este componente de "predictibilidad" es uno de los puntos sobre los que diverge Hayek de Veblen respecto a las instituciones, pues aquel concibe las instituciones como

\footnotetext{
${ }^{5}$ Citado por Ayala, José. Instituciones y economía. México, F. C. E., 2000, p. 35.
} 


\section{REVISTA VIRTUAL VIA INVENIENDI ET IUDICANDI \\ "CAMINO DEL HALLAZGO Y DEL JUICIO"}

http://viei.usta.edu.co/ E-MAIL: revistainveniendi@usantotomas.edu.co

"consecuencias no planeadas de la acción humana, de tal modo que las estructuras reales que se producen y sus efectos no son predecibles para los individuos que influyeron en su desarrollo" (Nelson y Sampat, 2001, p. 24). Las instituciones son para Veblen "hábitos mentales predominantes con respecto a relaciones y funciones particulares del individuo y de la comunidad" (Veblen, 1992, p. 196), donde la tradición y el conservadurismo son patrones que favorecen cierta inercia social. A pesar de esta diferencia entre Hayek y Veblen existe, a nivel de lo institucional, una evidente proximidad sobre todo en lo que respecta al "evolucionismo" y a las reservas sobre la racionalización de los procesos informativos: "...la idea de que las instituciones definen las reglas de comportamiento puede significar bien que las reglas imponen restricciones o bien que el comportamiento sigue un conjunto de reglas [...]. Es claro que para Hayek y Veblen la noción de instituciones tiene esta segunda connotación. Su posición es que el comportamiento sigue un patrón regular, que debe ser explicado mediante argumentos adicionales, más profundos o distintos del concepto de racionalidad informada" (Nelson y Sampat, 2001, p. 23).

Según John Commons,

A veces, institución significa el marco de leyes o derechos naturales dentro de los cuales los individuos actúan como reclusos. A veces significa el comportamiento de los reclusos. A veces se considera institucional a todo lo 


\section{REVISTA VIRTUAL VIA INVENIENDI ET IUDICANDI \\ "CAMINO DEL HALLAZGO Y DEL JUICIO"}

http://viei.usta.edu.co/ E-MAIL: revistainveniendi@usantotomas.edu.co

que se añade o critica a la economía clásica o hedonista. A veces es institucional todo lo que sea "comportamiento económico". A veces parece ser economía institucional todo lo que sea "dinámico" en vez de "estático", o "proceso" en vez de mercancías, o actividad en vez de sentimientos, o acción de masas en vez de acción individual, o administración en vez de equilibrio, o control en vez de laissez faire (2003, p. 191).

Hablar de instituciones no deja de presentar una posición de enfrentamiento a la ortodoxia económica en lo que respecta a su aislamiento, purismo e individualismo (al menos en su estructura metodológica, es decir en sus características fundamentales). No obstante, esta reacción no desampara la dimensión del sujeto sino que por el contrario demuestra que son precisamente las instituciones las que desarrollan sus escenarios de libertad. Al superar algunos escollos semánticos, Commons agrega: "Si nos empeñamos en encontrar una circunstancia universal, común a todo el comportamiento conocido como institucional, podemos definir una institución como acción colectiva que controla, libera y amplía la acción individual" (Loc. cit.).

La nueva microeconomía accede al análisis de aquellas relaciones y creencias que no dependen exclusivamente de la evaluación y elección de individuos aislados sino como conjunto de normas que rige la interacción humana. De tal forma, en oposición al modelo walrasiano, reemplaza la tesis de mercado por la 


\section{REVISTA VIRTUAL VIA INVENIENDI ET IUDICANDI \\ "CAMINO DEL HALLAZGO Y DEL JUICIO"}

http://viei.usta.edu.co/ E-MAIL: revistainveniendi@usantotomas.edu.co

del contrato, lo que supone costos transaccionales definidos como aquellos que sufragan los agentes en virtud de los problemas de información e incertidumbre.

Los individuos deben asegurarse que los contratos prevean la mayor cantidad de eventualidades al menor costo; y dotarse además de los medios necesarios para hacer respetar las cláusulas contractuales. La nueva microeconomía analiza los intercambios estudiando la forma en que se realizan los contratos, entre agentes racionales, con diferente disponibilidad de información y para modos distintos de coordinación de decisiones individuales. Por lo anterior, la nueva microeconomía de la información recibe algunas veces el calificativo de "nueva economía institucional" (Cahuc, 1996, p. 11).

\section{El azar y la teoría de juegos}

La economía estableció el principio de la perfecta información como mecanismo fundamental de su racionalidad, sin considerar diferentes escalas de valores exógenos que, a la postre, propiciaron una suerte de heterodoxia y conformaron alrededor de ella escuelas entre las cuales se cuentan el public choice, la nueva economía institucional y el análisis económico del derecho, donde la economía de la información (asimetría informacional) juega un rol de primer orden. La ruptura fundamental por parte de estas corrientes consiste en el rescate del análisis de 


\section{REVISTA VIRTUAL VIA INVENIENDI ET IUDICANDI \\ "CAMINO DEL HALLAZGO Y DEL JUICIO"}

http://viei.usta.edu.co/ E-MAIL: revistainveniendi@usantotomas.edu.co

entidades asociativas que no dependen de la valoración ni de la escogencia de "individuos aislados". Por eso, en los escenarios no sólo del derecho o de la economía sino de la interacción social en su gigantesco conjunto, la incertidumbre suele presentarnos el predicamento de los pagos de una elección, sea errada o acertada, en las más insospechadas dimensiones, y de ahí la necesidad de atender a los aspectos del azar como una categoría inseparable de la sociedad y, por supuesto, de la naturaleza humana.

El ebrio que improvisa un mandato absurdo, el soñador que se despierta de golpe y ahoga con las manos a la mujer que duerme a su lado ¿no ejecutan, acaso, una secreta decisión de la Compañía? Ese funcionamiento silencioso, comparable al de Dios, provoca toda suerte de conjeturas. Alguna abominablemente insinúa que hace ya siglos que no existe la Compañía y que el sacro desorden de nuestras vidas es puramente hereditario, tradicional; otra la juzga eterna y enseña que perdurará hasta la última noche, cuando el último dios anonade el mundo. Otra declara que la Compañía es omnipotente, pero que sólo influye en cosas minúsculas: en el grito de un pájaro, en los matices de la herrumbre y del polvo, en los entresueños del alba. Otra, por boca de heresiarcas enmascarados, que no ha existido nunca y no existirá. Otra, no menos vil, razona que es indiferente afirmar o negar la realidad de la tenebrosa corporación, porque 


\section{REVISTA VIRTUAL VIA INVENIENDI ET IUDICANDI \\ "CAMINO DEL HALLAZGO Y DEL JUICIO"}

http://viei.usta.edu.co/ E-MAIL: revistainveniendi@usantotomas.edu.co

Babilonia no es otra cosa que un infinito juego de azares (Borges, 1999, p. $57-58)$.

La gran mayoría de veces se asume el resultado de lo que se ignora como producto de una naturaleza misteriosa e inaccesible, o simplemente se aceptan sus consecuencias y designios como predicados de una categoría infinitamente aleatoria que suele considerarse ineludible: el azar. Cuando hacemos referencia a él, resulta imposible no aludir a una probabilidad, aunque sea mínima, de que un suceso determinado ocurra. Si bien la teoría de juegos mantiene nexos conceptuales con la inferencia estadística, su esencia radica fundamentalmente en el análisis de las estrategias. Tal vez esta característica haya contribuido a su reciente y vertiginoso desarrollo, involucrado en la planeación y determinación de fenómenos contemporáneos altamente ligados al tejido histórico del siglo XX, entre ellos la guerra.

El matemático John von Neumann y el economista Oskar Morgenstern publican Theory of Games and Economic Behavior en 1944, texto pionero de una modalidad de análisis que marcará el rumbo de futuros progresos en la economía de la incertidumbre y la información, y de ahí al análisis económico del derecho y la teoría de la elección pública, sobre todo a nivel del escenario contractual. En el año 1994 la Academia Sueca otorga el Premio Nobel de Economía a John Harsanyi, John Nash y Reinhart Selten por sus aportes en teoría de juegos; y más 


\section{REVISTA VIRTUAL VIA INVENIENDI ET IUDICANDI \\ "CAMINO DEL HALLAZGO Y DEL JUICIO"}

http://viei.usta.edu.co/ E-MAIL: revistainveniendi@usantotomas.edu.co

recientemente, en el 2001, a George Akerlof, Michael Spence y Joseph Stiglitz en

reconocimiento a sus trabajos en información asimétrica. Pero independientemente de su nominación al premio, es evidente que en las últimas décadas buena parte de la producción de las escuelas económicas ha gravitado de una u otra forma en torno al análisis de la información con base en la teoría de juegos.

Hemos de partir de un concepto fundamental que se conjuga con la omnipresencia del azar o de la información imperfecta, y consiste en que "la información es costosa". Dado ese carácter, la economía de la información, la economía neoinstitucional y el análisis económico del derecho, bajo presupuestos microeconómicos, analizan el "problema" a partir de una serie de categorías que serán expuestas en el siguiente aparte teniendo como principal referente el contrato.

En términos de la economía de la información, toda relación contractual implica una distribución de conocimientos pertinentes y por ende la asimetría se presenta cuando uno de los agentes goza de mayor información relevante respecto a la que posee el otro, lo cual condiciona los términos y el cumplimiento de los contratos. En el escenario contractual, la información juega un papel fundamental no sólo en el orden del pacto como tal sino del ejercicio mismo de la relación. Para explicar esas categorías, es necesario ilustrar, aunque de manera breve y general, los 


\section{REVISTA VIRTUAL VIA INVENIENDI ET IUDICANDI \\ "CAMINO DEL HALLAZGO Y DEL JUICIO"}

http://viei.usta.edu.co/ E-MAIL: revistainveniendi@usantotomas.edu.co

elementos esenciales de sus razonamientos y proposiciones a partir de la teoría de juegos. El ejemplo más citado, y utilizado para recrear esta última consiste en la composición de una circunstancia marcada por la presencia de dos individuos, una estructura de normas, y un repertorio de posibilidades establecidas: el dilema del prisionero. Dos individuos (A y B) son apresados y sindicados de quebrantar la ley. Se encuentran incomunicados, lo que implica que cada uno de ellos ignora qué esta pasando con el otro, pero a ambos se les anticipa un sistema de pagos (sanciones) dependiendo de la información que aporten (entiéndase de su colaboración con la justicia). En las Filas estableceremos el dominio del prisionero A y en las columnas el de B, y apuntaremos en cada par ordenado (A, B) los pagos a la información reportada por cada uno.

Opción I: si ambos sindicados confiesan el delito (SI,SI) cada uno de ellos obtendrá un pago de cinco años de cárcel.

PRISIONERO B

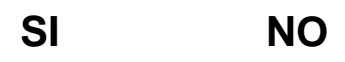

SI

\begin{tabular}{|c|c|}
\hline$-5,-5$ & \\
Opción I & \\
\hline
\end{tabular}

PRISIONERO A

\section{Diagrama 1}




\section{REVISTA VIRTUAL VIA INVENIENDI ET IUDICANDI \\ "CAMINO DEL HALLAZGO Y DEL JUICIO"}

http://viei.usta.edu.co/ E-MAIL: revistainveniendi@usantotomas.edu.co

Opción II: Si A confiesa (SI) y B elude su responsabilidad (NO), el pago será un año de prisión para A, quien confesó, y 10 años para B.

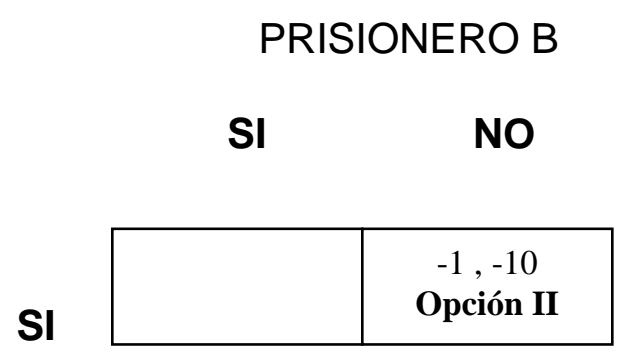

PRISIONERO A

\section{Diagrama 2}

La opción III consiste en la pareja ordenada de respuestas ( NO, SI ), la que acarreará un pago igual al de la opción II, un año para el que confiese y diez para el elusor, en caso de negar A y confesar B $(-10,1)$ como se aprecia en el diagrama 3.

Por último, la opción IV implica la negación del delito por ambos agentes (NO, NO) con lo cual la autoridad carece de pruebas para llevar a término la acusación, pero de todas formas hará lo conducente para que los prisioneros cuenten con un mínimo de dos años de prisión para cada uno $(-2,-2)$, lapso que se estima 


\section{REVISTA VIRTUAL VIA INVENIENDI ET IUDICANDI \\ "CAMINO DEL HALLAZGO Y DEL JUICIO"}

http://viei.usta.edu.co/ E-MAIL: revistainveniendi@usantotomas.edu.co

apropiado para concluir la acusación por falta de pruebas. Así, podemos expresar las opciones en una matriz de pagos del siguiente tenor:

PRISIONERO B
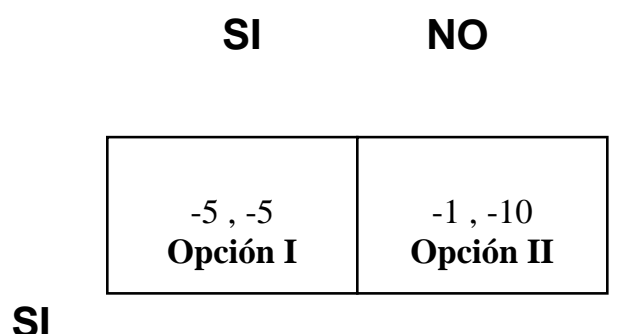

SI

PRISIONERO A

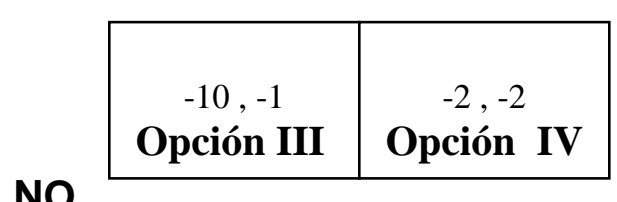

\section{Diagrama 3}

Los términos de la utilidad de cada prisionero (jugador) están expresados en valores negativos que representan los años de condena, por tanto los pagos reportados en la opción IV (dos años de cárcel para cada uno) sería viable, en primera instancia, sólo en el evento en que existiera la posibilidad de una negociación entre ellos que implicara un compromiso de silencio (no confesar). Ahora bien, aun en el evento de que pudieran comunicarse y pactarlo, no sería razonable para ninguno de los dos cumplir el acuerdo ya que el jugador $\mathrm{A}$, suponiendo que cumple lo pactado, corre el peligro inminente de ser traicionado por B en caso de que decida confesar, circunstancia que llevaría a éste último a 


\section{REVISTA VIRTUAL VIA INVENIENDI ET IUDICANDI \\ "CAMINO DEL HALLAZGO Y DEL JUICIO"}

http://viei.usta.edu.co/ E-MAIL: revistainveniendi@usantotomas.edu.co

obtener un pago de un año de prisión y por lo que, complementariamente, A se vería condenado a diez años. En ese orden de ideas, dada una hipotética negociación no sería racional cumplirla para ninguno de los dos ya que, cualquiera de ellos que se niegue a confesar, promoverá el incentivo correspondiente al otro para no cumplir el contrato. La solución del juego se establece a partir de la confesión de los dos prisioneros cuyo pago será de cinco años de cárcel para cada uno formulada en la opción I.

Al interior del juego, existe un orden de decisiones que en el lenguaje propio de la teoría se conoce como estrategia. En nuestro ejemplo, la elección o decisión de uno de los jugadores por la opción I genera resultados superiores sin importar qué decisión tome el otro. Si uno de ellos confiesa, independientemente de la estrategia que decida adoptar el otro, lo llevará a un pago superior: obtendrá 5 años de cárcel en caso de que el otro confiese, y uno sólo en caso de que aquel se decida por no confesar. Este tipo de estrategia en que "Yo obtengo el mejor resultado posible independientemente del que obtengas tú, y tú obtienes el mejor resultado posible independientemente del que obtenga yo", es una estrategia dominante por cuanto se considera óptima para un jugador, independientemente de la que elija su adversario. Igualmente, una estrategia puede resultar "estable" en el evento de que ninguno de los jugadores se vea incentivado a abandonarla, so pena de salir perdiendo. Digamos que cualquiera de los dos prisioneros analiza sus pagos mínimos, cuales son diez y cinco años de prisión (uno y dos años 


\section{REVISTA VIRTUAL VIA INVENIENDI ET IUDICANDI \\ "CAMINO DEL HALLAZGO Y DEL JUICIO"}

http://viei.usta.edu.co/ E-MAIL: revistainveniendi@usantotomas.edu.co

serían los pagos máximos) y decide optar por el pago máximo entre los mínimos, lo cual corresponde a cinco años (confesar, asumiendo que el otro en su decisión le depare lo peor, es decir, que también confiese). Esta estrategia de optar por el valor máximo entre los mínimos se conoce como estrategia maximin, la cual tendrá importantes implicaciones en la "posición original" de John Rawls.

Ahora bien, en el dilema del prisionero no existe negociación previa (los sindicados se encuentran incomunicados) lo cual, en escenarios normales, se estima altamente excepcional. La convención, por el contrario supone y exige esa negociación. Pero veamos en el siguiente ejemplo ${ }^{6}$ qué puede suceder con los términos y el cumplimiento del acuerdo en esa nueva circunstancia:

Sean dos únicas empresas que comparten por el mismo mercado (duopolio), los almacenes $\mathrm{X}$ e $\mathrm{Y}$ dedicados a la venta de electrodomésticos. Estas dos empresas compiten en las rebajas de enero, por lo cual se preparan para realizar gastos publicitarios a tal punto elevados que pueden implicar la pérdida de las utilidades derivadas de la campaña. Estas empresas se han puesto de acuerdo en obviar los costos en publicidad por lo que cada una espera obtener utilidades de 50 millones repartiéndose el mercado. No obstante, si una de ellas opta por "traicionar" lo pactado y se resuelve por invertir en su campaña y capturar la mayoría del consumo,

\footnotetext{
${ }^{6}$ Tomado de Pindyck, Robert y Daniel Rubinfeld. Microeconomía, Madrid, Prentice Hall Ibérica, 1998, Cap. 13 (La teoría de juegos y la estrategia competitiva), p. 414.
} 


\section{REVISTA VIRTUAL VIA INVENIENDI ET IUDICANDI \\ "CAMINO DEL HALLAZGO Y DEL JUICIO"}

http://viei.usta.edu.co/ E-MAIL: revistainveniendi@usantotomas.edu.co

podría obtener beneficios del orden de los 75 millones, y con ello la otra empresa perdería 25 millones.

EMPRESA Y

Coopera Traiciona

Coopera

\begin{tabular}{|l|l|}
\hline 50,50 & $-25,75$ \\
\hline
\end{tabular}

EMPRESA X

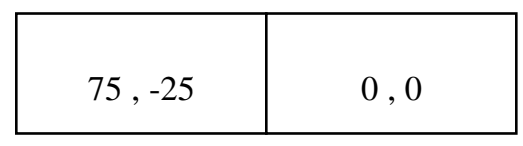

Diagrama 4

El gerente de $\mathrm{X}$ analiza las opciones de su matriz de pagos llegando a la conclusión de traicionar: si Y permanece fiel al acuerdo, el pago para la traición de $\mathrm{X}$ sería superior al reportado por su cumplimiento; y en caso de que $\mathrm{Y}$ opte por traicionar, X obtendrá un pago mayor traicionándola también. Si bien el Estado de Rousseau se asimila a un juego cooperativo, el Estado hobbesiano está muy lejos de ese propósito. De aquí que el componente de incertidumbre tenga como estaciones obligatorias la teoría de juegos y el azar. No obstante, en el orden del contrato se aprecian elementos que satisfacen el requerimiento material del cumplimiento de acuerdos y los presupuestos económicos que describen alguna forma de eficiencia en el uso mancomunado de los recursos. Esto se halla implícito en el hecho de que los agentes son conscientes de sus respectivas expectativas y destrezas, es decir, poseen la información suficiente no sólo para 


\section{REVISTA VIRTUAL VIA INVENIENDI ET IUDICANDI \\ "CAMINO DEL HALLAZGO Y DEL JUICIO"}

http://viei.usta.edu.co/ E-MAIL: revistainveniendi@usantotomas.edu.co

transar su respectivo precio sino para ordenarlas de tal forma que hagan posible la ejecución del proyecto.

Aproximando el orden social a la mecánica de los "juegos", Buchanan y Brennan muestran su inconformidad con la forma en que la economía se vale de la parábola de un Robinson Crusoe (personaje cuya circunstancia ilustra una suerte de imposibilidad para el derecho) para explicar el problema económico del hombre que se enfrenta a recursos escasos, y cómo extrapola sus mecanismos de elección hasta llevarlo a un medio social omitiendo la interacción de los individuos. Agregan que "los individuos hacen frente a elecciones en un entorno social en el que la existencia y el comportamiento de las demás personas, junto con las instituciones que limitan su conducta, son mucho más importantes que los condicionantes físicos de la naturaleza" (Buchanan y Brennan, 1985, p. 39). Igualmente advierten que, al igual que en un juego de poker existe un reglamento que posibilita y estructura la mecánica del "pasatiempo" ${ }^{7}$ como tal, existe otra visión que lo define y determina: el orden de las estrategias. Lo mismo ocurre con las reglas de tránsito: es claro que el trayecto de un sitio a otro de la ciudad se halla regulado y controlado por un sistema de normas, pero las estrategias del conductor son las que en últimas definen la ejecución de su objetivo, como son, por decirlo de alguna manera, las rutas que escoja, el tiempo que estime conveniente para hacerlo, el nivel de seguridad, el vehículo, etc. Se podría pensar

\footnotetext{
${ }^{7}$ Para evitar confusiones semánticas, se hace necesario aquí emplear un término diferente a “juego".
} 


\section{REVISTA VIRTUAL VIA INVENIENDI ET IUDICANDI \\ "CAMINO DEL HALLAZGO Y DEL JUICIO"}

http://viei.usta.edu.co/ E-MAIL: revistainveniendi@usantotomas.edu.co

que, aludiendo a la interacción social que hemos traído a colación permanentemente, las estrategias de nuestro conductor estarán signadas por las estrategias (desconocidas) del resto de usuarios con quienes comparta la vía. Pero la reglamentación supone un límite de certidumbre respecto a sus posibles combinaciones. "Las reglas proporcionan a cada actor la posibilidad de predecir el comportamiento de los demás. Esta predictibilidad toma la forma de una información o de un límite informativo acerca de las acciones de quienes se hallan implicados en la interacción" (Buchanan y Brennan, 1985, p. 46).

En términos de predictibilidad, afirma Douglas North que "Las instituciones reducen la incertidumbre por el hecho de que proporcionan una estructura a la vida diaria" (2001, p. 14), luego de lo cual añade: "La función principal de las instituciones en la sociedad es reducir la incertidumbre estableciendo una estructura estable (pero no necesariamente eficiente) de la interacción humana" (p. 16). Atendiendo a estos argumentos, las normas como elemento de predictibilidad, se eluden o se dan por sentadas la eficiencia, la justicia y los requerimientos del orden que les han dado origen (el aspecto interno de las reglas, en palabras de H. L. A. Hart), y cuyo constructo, para efectos de nuestro análisis, se reduce a la observancia, tanto la propia como la de los demás, lo cual generará un determinado repertorio de expectativas y estrategias de interacción. Podríamos ilustrar este argumento con el hecho de que para estar exento de accidentes no basta con la prudencia del sujeto sino que su nivel de seguridad depende también 


\section{REVISTA VIRTUAL VIA INVENIENDI ET IUDICANDI \\ "CAMINO DEL HALLAZGO Y DEL JUICIO"}

http://viei.usta.edu.co/ E-MAIL: revistainveniendi@usantotomas.edu.co

del comportamiento de los demás, sobre el cual el individuo no posee más que una aproximación conjetural. El caso del uso de direccionales por parte de muchos conductores en las principales ciudades colombianas, sea para girar o para cambiar de carril, y la respuesta de quienes comparten la vía, ilustra el predicamento de las muchas cosas que "funcionan" adecuadas a comportamientos diferentes a su diseño inicial.

\section{Una nota sobre el contrato y la economía de la información}

La matemática y la economía han combinado esfuerzos para establecer las posibles soluciones a los desafíos presentados por la incertidumbre, valiéndose de instrumentos y categorías hasta cierto punto cuantificables. La relación característica de la economía de la información está compuesta por un individuo que posee información relevante llamado agente, y otro llamado principal que suele estar menos informado que aquel. Podemos decir que el principal $(P)$ diseña el contrato y se lo ofrece al agente (A), de tal forma que asegure, hasta cierto punto, que éste cumpla el compromiso de realizar alguna labor. El único albur estriba en el componente de azar atribuible a la naturaleza $(\mathrm{N})$, después de lo cual la relación producirá los resultados y pagos esperados. La secuencia contractual en términos de información estaría dada por el siguiente orden ${ }^{8}$ :

\footnotetext{
${ }^{8}$ Todas las estructuras siguientes han sido expuestas por Inés Macho y David Castrillo, en Introducción a la economía de la información, Barcelona, Ariel, 1994.
} 


\section{REVISTA VIRTUAL VIA INVENIENDI ET IUDICANDI \\ "CAMINO DEL HALLAZGO Y DEL JUICIO"}

http://viei.usta.edu.co/ E-MAIL: revistainveniendi@usantotomas.edu.co

- P diseña el contrato

- A acepta o rechaza

- A realiza un esfuerzo

- N juega

- Resultados y pagos

La economía de la información interviene en escenarios en que la información es asimétrica, ofreciendo las siguientes categorías de análisis:

1. Riesgo moral: Se presenta cuando el principal no puede tener acceso a la información sobre el comportamiento del agente. Supóngase una empresa que contrata a un vendedor de enciclopedias puerta a puerta. El principal, o sea la empresa, en caso de querer conseguir información fiable respecto del comportamiento de su vendedor tendría que incurrir en mayores erogaciones como el costo de un "organismo vigilante" que pueda dar fe de las faenas del vigilado. "Un problema de riesgo moral se presenta cuando la acción del agente no es verificable, o cuando el agente recibe información privada una vez iniciada la relación. En las situaciones con riesgo moral los participantes disponen de la misma información en el momento de establecer la relación" (Macho y Castrillo, 1994, p. 21). Pero la asimetría radica en que, una vez firmado el contrato, el principal no puede observar el desempeño del agente. Por lo cual esta variable no puede ser incluida en el contrato, y por tanto el pago del agente no puede 


\section{REVISTA VIRTUAL VIA INVENIENDI ET IUDICANDI \\ "CAMINO DEL HALLAZGO Y DEL JUICIO"}

http://viei.usta.edu.co/ E-MAIL: revistainveniendi@usantotomas.edu.co

depender del esfuerzo que incorpora y para el que se le ha contratado. De tal forma, la solución a este predicamento está en construir una estrategia óptima para el principal mediante algún tipo de incentivo, como podrían ser las comisiones sobre ventas. La secuencia contractual en presencia de riesgo moral se establecería entonces de la siguiente manera:

- P diseña el contrato

- A acepta o rechaza

-A realiza un esfuerzo no verificable

- N juega

- Resultados y pagos

2. Selección adversa: Cuando el agente, con anterioridad a la firma del contrato, tiene a su haber información relevante para la relación contractual que es ignorada por el principal. Es decir, conoce antes de firmar el contrato un elemento relevante de la relación a la que el principal no tiene acceso. Los contratos en los seguros de vehículos es de selección adversa por cuanto el principal puede acceder a información que le permita controlar el comportamiento del agente dentro de la relación, pero la solución óptima depende del tipo de agente con que esté tratando. Si bien el principal puede informarse sobre el desempeño del agente al interior del contrato (cosa que no puede cuando se presenta riesgo moral) la información imperfecta se establece sobre las características del agente, es decir, 


\section{REVISTA VIRTUAL VIA INVENIENDI ET IUDICANDI \\ "CAMINO DEL HALLAZGO Y DEL JUICIO"}

http://viei.usta.edu.co/ E-MAIL: revistainveniendi@usantotomas.edu.co

el principal en efecto sabe que éste puede presentarse de múltiples formas, pero no puede distinguirlas. Por ejemplo, cuando un conductor acude a una empresa aseguradora, ésta puede estar al tanto del comportamiento de su cliente, pero el problema informacional estriba en el hecho de ignorar si ese cliente acostumbra conducir a gran velocidad o por el contrario es precavido, si respeta las señales de tránsito o si es proclive al alcohol, etc. En este caso, la "naturaleza" o el "azar" juegan primero en la secuencia contractual al elegir ellos el tipo de agente. La selección adversa opera, entonces, en escenarios de información asimétrica con anterioridad a la firma del contrato. La solución del problema de selección adversa puede estar en seleccionar, por parte del principal, un mecanismo de información sobre las calidades del individuo, tal y como lo efectúa en las centrales de riesgo crediticio.

- N elige el tipo de $A$

- P diseña el contrato

- A acepta o rechaza

- A realiza un esfuerzo

- N juega

- Resultados y pagos

3. Teoría de la señal: Una de las partes posee información relevante para la relación y procura con su comportamiento darla a conocer por medio de una serie 


\section{REVISTA VIRTUAL VIA INVENIENDI ET IUDICANDI \\ "CAMINO DEL HALLAZGO Y DEL JUICIO"}

http://viei.usta.edu.co/ E-MAIL: revistainveniendi@usantotomas.edu.co

de señales a la otra parte. Con anterioridad a la oferta del contrato por parte del principal, el agente optará por alguna señal que le permita influir en la confección del contrato. Tal es el caso de los títulos académicos que suponen una serie de virtudes por parte de sus poseedores: esfuerzo, dedicación, cultura, orden, conocimiento, etc, y que en últimas se convierten en una señal que "habla" positivamente de un individuo, procurándole mayores garantías, por ejemplo, con ocasión de un posible contrato de trabajo. La asimetría en este caso estriba en que las virtudes que los títulos hacen predecibles y generan las retribuciones del contrato no proporcionan el mismo nivel de seguridad sobre su desempeño real.

- $\mathrm{N}$ elige el tipo de $\mathrm{A}$

- A envía una señal

- P diseña el contrato

- A acepta o rechaza

- A realiza un esfuerzo

- N juega

- Resultados y pagos

\section{Conclusiones}

Para concluir, estimando la información en términos de la secuencia del contrato, diremos que se presenta Riesgo Moral cuando la información asimétrica se 


\section{REVISTA VIRTUAL VIA INVENIENDI ET IUDICANDI \\ "CAMINO DEL HALLAZGO Y DEL JUICIO"}

http://viei.usta.edu.co/ E-MAIL: revistainveniendi@usantotomas.edu.co

produce tras la firma del contrato, Selección Adversa cuando la asimetría se presenta antes de la firma del contrato, y Señalización cuando la parte informada, antes de establecer el acuerdo, trata de incidir en la elaboración del contrato mediante señales.

En escenarios de selección adversa, se está en presencia de información incompleta, la cual consiste en que el sistema de precios no es suficiente para reportar la información pertinente para el intercambio lo que se traduce en que una parte de los participantes desconoce los resultados efectivos (pagos) asociados con sus decisiones, una carencia en el medio convencional que impide la transmisión eficiente de los términos informativos con los cuales los individuos adecúan su comportamiento. De otro lado, el riesgo moral implica la presencia de información asimétrica que consiste en la desigualdad de conocimientos por parte de los contratantes, por lo que una de las partes se hallará mejor informada.

La economía de la información responde así al análisis del comportamiento de los individuos en escenarios donde la información es insuficiente y por ende genera resultados que son asumidos como costos, en el más amplio sentido de la palabra. Así mismo, en virtud de la imposibilidad de separar la incertidumbre del azar, la teoría de juegos nos presenta dos posibles estrategias de comportamiento: cooperar o no cooperar en términos contractuales. Por otra parte, en palabras de Hayek: "El juego es realmente claro ejemplo de un proceso en el 


\section{REVISTA VIRTUAL VIA INVENIENDI ET IUDICANDI \\ "CAMINO DEL HALLAZGO Y DEL JUICIO"}

http://viei.usta.edu.co/ E-MAIL: revistainveniendi@usantotomas.edu.co

que la obediencia a unas reglas generales por sujetos que persiguen fines distintos e incluso opuestos da origen a un orden general" (1990, p. 228), pero conviene recordar que el mecanismo de la mano invisible con fundamento en el propio interés dista mucho de ser congruente con la racionalidad colectiva que nos sugiere el Dilema del Prisionero, elemento esencial en la configuración y asunción del orden social. Así, la información que manejan los individuos separadamente no puede estimarse como insumo del conocimiento social, pues si bien las instituciones reducen la incertidumbre, la democracia liberal exige la dispersión de datos y la descentralización de la información como elementos que garantizan de alguna forma tanto las libertades individuales en lo político como los presupuestos del mercado en lo económico.

\section{REFERENCIAS BIBLIOGRÁFICAS}

Ayala, José (2000). Instituciones y economía. México: F. C. E.

Barry, Norman (1997). "La tradición del orden espontáneo". Revista Acta Académica, Universidad Autónoma de Centroamérica. Recuperado el 12 de agosto de 2000, de http://www.uaca.ac.cr/acta/1997nov/norman.htm

Borges, Jorge Luis (1999). "La lotería en Babilonia”, en Ficciones. Madrid: EspasaCalpe. 


\section{REVISTA VIRTUAL VIA INVENIENDI ET IUDICANDI \\ "CAMINO DEL HALLAZGO Y DEL JUICIO"}

http://viei.usta.edu.co/ E-MAIL: revistainveniendi@usantotomas.edu.co

Buchanan, James y Geoffrey Brennan (1985). La Razón de las normas. Barcelona: Ed. Unión.

Cahuc, Pierre (1996). La Nueva Microeconomía. Bogotá: Universidad Nacional de Colombia-Ed. Alfaomega.

Commons, John (2003). "Economía Institucional". Revista Economía institucional, Universidad Externado de Colombia. № 8, I semestre de 2003, pp. 191-201.

Cuevas, Homero (1993). Introducción a la Economía. Bogotá: Universidad Externado de Colombia.

Galbraith, John Kenneth (1992). Historia de la economía, Barcelona: Ariel.

Gray, John (1994). Liberalismo. Madrid: Alianza.

Habermas, Jürgen (1990). Teoría de la Acción Comunicativa. (t. I) Buenos Aires: Taurus.

Hayek, Friedrich (1986). Camino de servidumbre. San José de Costa Rica: Universidad Autónoma de Centroamérica. 


\section{REVISTA VIRTUAL VIA INVENIENDI ET IUDICANDI \\ "CAMINO DEL HALLAZGO Y DEL JUICIO"}

http://viei.usta.edu.co/ E-MAIL: revistainveniendi@usantotomas.edu.co

Hayek, Friedrich (1990). La fatal arrogancia. Los errores del socialismo. Madrid: Ed. Unión.

Hayek, Friedrich (1996). Los fundamentos de la libertad. Barcelona: Ed. Unió.

Hayek, Friedrich (1999). "El uso del conocimiento en la sociedad". Revista Cuadernos de economía, Universidad Nacional de Colombia, № 30, pp. 331-345.

Macho, Inés y David Castrillo (1994). Introducción a la economía de la información. Barcelona: Ariel.

Morin, Edgar (1996). Introducción al pensamiento complejo. Barcelona: Gedisa.

Nelson, Richard y Bhaven Sampat (2001). "Las instituciones como factor que regula el desempeño económico". Revista Economía institucional, Universidad Externado de Colombia. № 5, Il semestre de 2001, pp. 17-51.

North, Douglas (2001). Instituciones, cambio institucional y desempeño económico. México: F. C. E.

Pindyck, Robert y Daniel Rubinfeld (1998). Microeconomía. Madrid: Prentice Hall Ibérica. 


\section{REVISTA VIRTUAL VIA INVENIENDI ET IUDICANDI \\ "CAMINO DEL HALLAZGO Y DEL JUICIO"}

http://viei.usta.edu.co/ E-MAIL: revistainveniendi@usantotomas.edu.co

Popper, Karl (1994). En busca de un mundo mejor. Barcelona: Paidós.

Popper, Karl (1996). La miseria del historicismo. Madrid: Alianza.

Rawls, John (1997). Teoría de la justicia. México: F. C. E.

Schumpeter, Joseph (1984). Historia del análisis económico. México: F. C. E.

Stigler, George (2000). "El análisis económico de las políticas públicas: una súplica a los académicos". En Andrés Roemer (Compilador), Derecho y Economía, una revisión de la literatura. México: F. C. E.

Veblen, Thorstein (1992). Teoría de la clase ociosa. México: F.C. E.

Villa, Edgar (2002). "Una mirada al papel regulador del Estado". En Homero Cuevas (Ed.) Teorías jurídicas y económicas del Estado, Bogotá, Universidad Externado de Colombia. 